testicular tissue culture, and to Mrs Veronica Buckle for her help with the bone marrow preparations.

\section{References}

1 Yunis JJ. High resolution of human chromosomes. Science 1976;191:1268-70.

2 Escalante JA, Grunspun H, Frota-Pessoa O. Severe sexlinked mental retardation. J Genet Hum 1971;19:137-40.

3 Turner G, Till R, Art D. Marker X chromosomes, mental retardation and macro-orchidism. $N$ Engl $J$ Med 1978;299:1472.

4 Jacobs PA, Gerrard J, Hall J. More on marker X chromosomes, mental retardation and macro-orchidism. $N$ Engl $J$ Med 1979;300:737-8.

5 Sutherland GR. Heritable fragile sites on human chromosomes. II. Distribution, phenotypic effects and cytogenetics. Am J Hum Genet 1979;31:136-48.
6 Turner G, Eastman C, Casey J, McLeay A, Procopis P, Turner B. X linked mental retardation associated with macro-orchidism.J Med Genet 1975;12:367-71.

7 Cantú JM, Scaglia HE, Medina M, González-Diddi M, Morato T, Moreno ME. Inherited congenital normofunctional testicular hyperplasia and mental deficiency. Hum Genet 1976;33:323-33.

8 Meinhard E, McRae CU, Chisholm GD. Testicular biopsy in evaluation of male fertility. Br Med J 1973;3:577-81.

${ }^{9}$ Ferguson-Smith MA, Lennox B, Stewart JS, Mack WS. Klinefelter's syndrome. Memoirs of the Society for Endocrinology 1960;1:173-81.

Correspondence and requests for reprints to Dr P R Millard, EM Unit, Histopathology Department, Level 1, John Radcliffe Hospital, Headington, Oxford OX3 9DU.

\title{
Additional manifestations of the Neu-Laxova syndrome
}

\author{
SUSAN BECKWITT TURKEL, ALLAN J EBBIN, AND JOSEPH W TOWNER \\ Departments of Pathology and Pediatrics, University of Southern California School of Medicine, \\ Los Angeles County-USC Medical Center, Los Angeles, California 90033, USA.
}

SUMMARY A newborn female with intrauterine growth retardation, bilateral cleft lip and palate, absent external nares and eyelids, low set ears, short contracted limbs, webbed digits, intestinal malrotation, and unilateral renal agenesis is reported. These multiple malformations are considered part of the Neu-Laxova syndrome.

The Neu-Laxova syndrome is a rare, autosomal recessive disorder associated with severe malformations and neonatal death. Fourteen cases have been reported so far, ${ }^{1-5}$ and the purpose of our report is to describe another case with additional anomalies.

\section{Case report}

A severely malformed female infant was born to apparently non-consanguineous Mormon parents. The father, aged 24 , is adopted and knows nothing of his background. The mother, aged 23 , has one brother, one full sister, and one paternal half-sister. Her full sister has one normal son, and her half-sister has had one miscarriage and three normal children. The maternal grandmother had 11 pregnancies, eight of which resulted in spontaneous abortion. A great-aunt is said to have had 'mongolism'. The

Received for publication 16 July 1982.

Accepted for publication 20 October 1982. mother, her mother, her uncle, and a cousin have psoriasis. The parents divorced soon after the birth of this child. The mother has remarried and has had a normal infant with her second husband.

Both parents had a history of drug abuse with hashish, marijuana, lysergic acid diethylamide, mescaline, amphetamines, and phencyclidine several years before the birth of their child. When the mother first became pregnant, she was taking Robaxin and Norgesic, but she discontinued them when pregnancy was confirmed. She spotted briefly early in pregnancy, in the fourth month took Gantrisin for a urinary tract infection, and in the sixth month took aspirin, Actifed, penicillin, and cough syrup for a 'flu-like' illness. On thyroid tablets intermittently for several years, the mother took thyroid replacement and antenatal vitamins daily throughout pregnancy. She states that she never felt strong fetal movements during the pregnancy.

At approximately 36 weeks' gestation, a female infant was born by spontaneous vaginal delivery. A heart beat was detected for a brief period. After death the body was preserved intact in formalin and later sent to the Los Angeles County-University of Southern California Medical Center for necropsy.

The body weighed $940 \mathrm{~g}$. Body measurements included: head circumference $23.5 \mathrm{~cm}$, chest circumference $24.0 \mathrm{~cm}$, crown-heel length $34.0 \mathrm{~cm}$, and crown-rump length $21.0 \mathrm{~cm}$. The infant had 


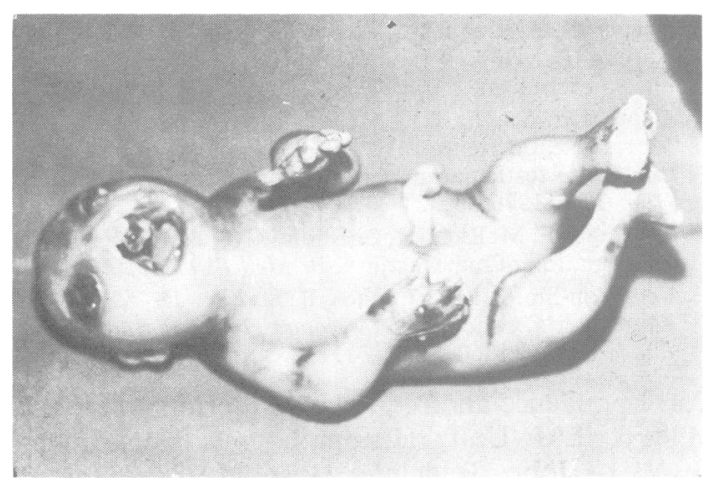

FIGURE The proband. Note the small head, absent eyelids, bilateral cleft lip and palate, short neck, shortened and contracted limbs, and broad hands and feet with small webbed digits. Unilateral renal agenesis and partial intestinal malrotation were found internally.

complete bilateral cleft lip and palate, absent external nares, and absent upper and lower eyelids (figure). The forehead was sloping and the head was small. The inner canthal distance was $2.4 \mathrm{~cm}$ and the outer canthal distance was $5.5 \mathrm{~cm}$. No colobomata were present. The ears were simple, symmetrical, low set, and $2.6 \mathrm{~cm}$ in length. A few scattered petechiae were noted on the skin. The thorax was broad and symmetrical with widely spaced nipples. The head appeared to arise directly from the trunk. There were contractures and proximal shortening of both the upper and lower extremities. The hands and feet were broad with small, partially webbed digits. The external genitalia were unremarkable.

On internal examination, the large intestine was noted to be partially malrotated with the appendix in the midline. The thoracic cavity was foreshortened. The stomach was an elongated tube-like structure associated with a small hiatus hernia. The pylorus, duodenum, small intestine, pancreas, liver, and biliary system were normal. The liver weighed $53 \mathrm{~g}$. The heart and lungs together weighed $21 \mathrm{~g}$ and were normally formed. The spleen weighed $2 \mathrm{~g}$ and the thymus weighed $1 \mathrm{~g}$. Both showed mild lymphoid depletion on microscopical examination and focal calcification of Hassall's corpuscles was found in the thymus. The right kidney and right ureter were absent. The left kidney weighed $4 \cdot 1 \mathrm{~g}$ and showed an irregular pattern of fetal lobulation. The single ureter inserted into the dome of a very contracted bladder to the left of the mid-line. The ovaries, fallopian tubes, and uterus were normal. The adrenals each weighed $1 \mathrm{~g}$ and were unremarkable.

Examination of the brain was difficult because of poor preservation. The gross configuration appeared very abnormal and disorganised without recognisable landmarks. On microscopical examination meninges, ependymal lining, and intervening disorganised neural tissue were found.

The placenta weighed $200 \mathrm{~g}$ after fixation. The segment of umbilical cord contained one artery and one vein. The placenta showed focal hyalinisation and calcification of third trimester villi with intervillous fibrin deposition.

Karyotyping, including Giesma banding, was के done on the mother's, father's, and maternal $\overrightarrow{0}$ grandmother's peripheral blood cultures. A minor variant chromosome, a fragile $16 \mathrm{q}$, was observed in $\vec{\omega}$ the mother's karyotypes from three culture preparations postpartum. An isochromatid constriction or break, located consistently at a 'fragile site' in i the distal third of the long arm of chromosome 16, $\dot{\omega}$ was found in 4 to $24 \%$ of cells studied. This finding is classified as a minor variant. ${ }^{6}$ ?

This case was referred to the Center for Birth 은 Defects Information Services, Boston, Massachu- setts, for evaluation. They were able to make the $\subseteq$ association with previous cases of the Neu-Laxova syndrome and provided us with the diagnosis.

\section{Discussion}

This severely malformed female infant exhibited multiple anomalies of the Neu-Laxova syndrome. ${ }^{1-5} \bar{\partial}$ This rare disorder is characterised by severe intra- $\stackrel{\varrho}{\not}$ uterine growth retardation, microcephaly, abnormal $\stackrel{\mathbb{Q}}{\stackrel{2}{2}}$ facies, short neck, arthrogryposis multiplex con- $\overrightarrow{\overrightarrow{0}}$ genita, short webbed digits, and central nervous $\frac{3}{3}$ system malformations. ${ }^{1-4}$ Hydrops, ichthyosis, and $\vec{\partial}$ epidermal desquamation have been described. Absent or hypoplastic lids, hypertelorism, everted lips, flat simple nose, and low set simple ears typify the facial features. Bilateral cleft lip and palate were $\dot{\sigma}$ found in addition in our case. Internal visceral malformations have included premature closure $\delta$ of the ductus arteriosus, lung hypoplasia, and 3 deformity of the liver. Unilateral renal agenesis and 을 partial intestinal malrotation have not been previously reported. Hypoplasia of Hassall's corpuscles has been described, ${ }^{1}$ but was not found in our case. $\frac{\bar{N}}{N}$ Microcephaly with premature closure of the sutures 0 and malformation of the brain are typical, with $N$

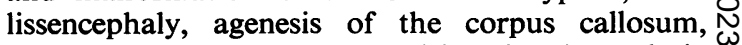
hypoplasia of the corpora quadrigemina, hypoplasia 0 of the cerebellum, and agenesis of the vermis reported. ${ }^{4}$ Placental hypoplasia ${ }^{3}$ and short umbilical $\stackrel{\circ}{\overparen{D}}$ cord ${ }^{134}$ have been reported, but single umbilical $\stackrel{\oplus}{\rightarrow}$ artery has not.

Consanguinity has been reported in the parents of affected sibs with this disorder, ${ }^{12}$ and an auto- $\mathbb{\mathbb { D }}$ somal recessive pattern of inheritance has been $\vec{\Phi}$ considered likely. ${ }^{4}$ The parents of our case were not $\frac{0}{0}$ 
known to be related, although consanguinity cannot be completely ruled out because the father was adopted. They were both Mormons, in whom kinship coefficients and genetic heterogeneity are low. ${ }^{8}$ The significance of the parental history of drug ingestion and the maternal minor chromosomal variant is unknown.

The authors wish to express their appreciation to Dr Marylou Buyse of the Center for Birth Defects Information Service for assistance in syndrome identification, and to $\mathrm{Dr}$ Blanche Bobbitt for editing the manuscript.

\section{References}

1 Neu RL, Kajii T, Gardner LI, Nagyfy SF, King S. A lethal syndrome of microcephaly with multiple congenital anomalies in three siblings. J Pediatr 1971;47:610-2.

2 Laxova R, Ohara PT, Timothy JAD. A further example of a lethal autosomal recessive condition in sibs. $J$ Ment Defic Res 1972;16:139-43.
${ }^{3}$ Povysilova V, Macek M, Salichova J, Seemanova E. Letalni syndrom mnonocetnych malformaci u tri sourozencu. Cesk Pediatr 1976;31:190-4.

4 Gennady IL, Lurie IW, Ostrowskaja TI, et al. Brief clinical observations: the Neu-Laxova syndrome-a distinct entity. Am J Med Genet 1979;3:261-7.

5 Curry CJR, Laurence KM, Scott CI, Opitz J, Hall JG. Further delineation of the Neu-Laxova syndrome. Clin Res $1981 ; 29: 130$ A.

6 Magenis RE, Hecht F, Lovrien EW. Heritable fragile site on chromosome 16: probable localization of haptoslobin locus in man. Science 1970;170:85-7.

7 Drets ME, Cardoso JH, Delfino A H, Carrace J. Familial normal/partial trisomy 16 with selective endoreplication in malformed proband. Cytogenetics 1970;9:333-50.

8 Jorde LB. The genetic structure of the Utah Mormons: migration analysis. Hum Biol 1982;54:583-97.

Correspondence and requests for reprints to $\mathrm{Dr}$ Susan Beckwitt Turkel, Department of Pathology, Los Angeles County-USC Medical Center, Women's Hospital Room 1-M-19, Los Angeles, California 90033, USA.

\title{
Intestinal obstruction and cystic fibrosis: antenatal ultrasound appearance
}

\author{
J SHALEV, R NAVON*, D URBACH†, S MASHIACH, AND B GOLDMAN* \\ Department of Obstetrics and Gynecology, *the Institute of Human Genetics, and $\dagger$ the Department of \\ Neonatology, Chaim Sheba Medical Center, Sackler School of Medicine, Tel-Aviv University, Tel-Hashomer, \\ Israel.
}

SUMMARY The diagnosis of cystic fibrosis in utero is based on amniotic fluid analysis. False negative results of this method underline the importance of antenatal ultrasonography to detect intestinal obstruction in affected fetuses.

Cystic fibrosis, the most common autosomal recessive genetic disorder in Caucasians, occurs in about one in 1600 births and follows simple autosomal recessive transmission. The disease affects glands and results in abnormal mucus secretion. As a result, intestinal obstruction resulting from meconium abnormality is often observed. Intrauterine diagnosis of cystic fibrosis using intestinal obstruction as a sonographic marker in a late stage of pregnancy is reported.

\section{Case report}

A 32 -year-old gravida 6 , para 4 , who had previously given birth to a child with cystic fibrosis, underwent

Received for publication 5 October 1982.

Accepted for publication 8 November 1982. sonographic examination and amniocentesis at 21 weeks' gestation. She had previously had two healthy children, one pregnancy was aborted after measles infection, and one child died at the age of 5 months of cystic fibrosis. The fifth pregnancy was terminated at 24 weeks' gestation as amniocentesis showed cystic fibrosis in the fetus (figure). In the present pregnancy, amniotic fluid analysis by Hoesli's method was negative' ${ }^{1}$ and a 'normal' fetus was diagnosed. On routine sonographic scanning at 17 and 21 weeks' gestation no pathological findings were observed. At 33 weeks' gestation ultrasonography showed overdistended bowel loops and polyhydramnios. The stomach, both kidneys, and the bladder were of normal shape. Repeated sonography at 35 and 37 weeks' gestation showed a similar picture. Small bowel obstruction was suspected. At 39 weeks a female infant weighing $2900 \mathrm{~g}$ was delivered spontaneously with an Apgar score of 10 at 1 and 5 minutes. The neonate appeared normal except for gross abdominal distension. On the first day of life meconium was not passed. Plain abdominal $x$-ray revealed small bowel dilation. Barium enema showed microcolon. Eight days of 